Atmos. Chem. Phys., 18, 14253-14269, 2018

https://doi.org/10.5194/acp-18-14253-2018

(C) Author(s) 2018. This work is distributed under

the Creative Commons Attribution 4.0 License.

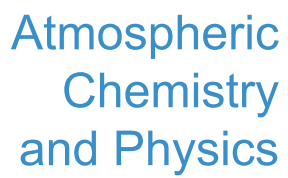

(c) (i)

\title{
The role of droplet sedimentation in the evolution of low-level clouds over southern West Africa
}

\author{
Christopher Dearden ${ }^{1, \mathrm{a}}$, Adrian Hill ${ }^{2}$, Hugh $\mathrm{Coe}^{1}$, and Tom Choularton ${ }^{1}$ \\ ${ }^{1}$ Centre for Atmospheric Science, School of Earth and Environmental Science, University of Manchester, Manchester, UK \\ ${ }^{2}$ Met Office, Exeter, UK \\ anow at: Centre of Excellence for Modelling the Atmosphere and Climate, School of Earth and Environment, \\ University of Leeds, Leeds, UK
}

Correspondence: Christopher Dearden (c.dearden@leeds.ac.uk)

Received: 18 March 2018 - Discussion started: 20 April 2018

Revised: 17 August 2018 - Accepted: 30 August 2018 - Published: 9 October 2018

\begin{abstract}
Large-eddy simulations are performed to investigate the influence of cloud microphysics on the evolution of low-level clouds that form over southern West Africa during the monsoon season. We find that, even in clouds that are not precipitating, the size of cloud droplets has a non-negligible effect on liquid water path. This is explained through the effects of droplet sedimentation, which acts to remove liquid water from the entrainment zone close to cloud top, increasing the liquid water path. Sedimentation also produces a more heterogeneous cloud structure and lowers cloud base height. Our results imply that an appropriate parameterization of the effects of sedimentation is required to improve the representation of the diurnal cycle of the atmospheric boundary layer over southern West Africa in large-scale models.
\end{abstract}

\section{Introduction}

During the months of June to September, the climate of southern West Africa (SWA) is dominated by the southwesterly flow of the West African Monsoon (WAM), which is principally driven by a north-south pressure gradient associated with the Saharan heat low and brings seasonal rains to the region (e.g. Sultan and Janicot, 2000; LeBarbé et al., 2002). Clouds, through their diabatic effects, are known to exert an influence on the WAM circulation. For example, a number of studies have explored the role of moist convection in the Sahel (e.g. Garcia-Carreras et al., 2013; Marsham et al., 2013; Birch et al., 2014), revealing that the diurnal cy- cle of latent heating and cloud radiative forcing affects the north-south pressure gradient and hence the northward advection of moisture.

Low-level clouds (LLCs) over SWA, with bases only a few hundred metres above ground level (a.g.l.), are also a common occurrence during the WAM season (e.g. Schrage and Fink, 2012; van der Linden et al., 2015), yet it is only recently that their role has been considered in detail. LLCs typically form near the Guinea coast sometime after sunset following the initiation of the southwesterly nocturnal low-level jet. The jet is linked to the low-level pressure gradient, supplying moisture to the Sahel region where it is mixed as a result of convection during the day (Parker et al., 2005; Lothon et al., 2008; Abdou et al., 2010; Bain et al., 2010). The clouds then spread northwards inland during the night (Schuster et al., 2013; van der Linden et al., 2015; Kalthoff et al., 2018), and typically persist until the late morning, after which they transition to broken cumulus and dissipate. Through their impact on surface solar irradiance, the LLCs play an important role in the evolution of the atmospheric boundary layer (BL) (Gounou et al., 2012) and the regional climate of West Africa (e.g. Knippertz et al., 2011; Hannak et al., 2017).

The most comprehensive observational study of the atmospheric BL over SWA was conducted recently by Kalthoff et al. (2018) during the DACCIWA field campaign (Knippertz et al., 2015a, 2017; Flamant et al., 2017). Between 14 June and 30 July 2016, intensive observations were made at three ground sites - Savé (Benin), Kumasi (Ghana), and Ile-Ife (Nigeria) - using a variety of instrumentation including infrared cloud cameras, radiosondes and wind profil- 


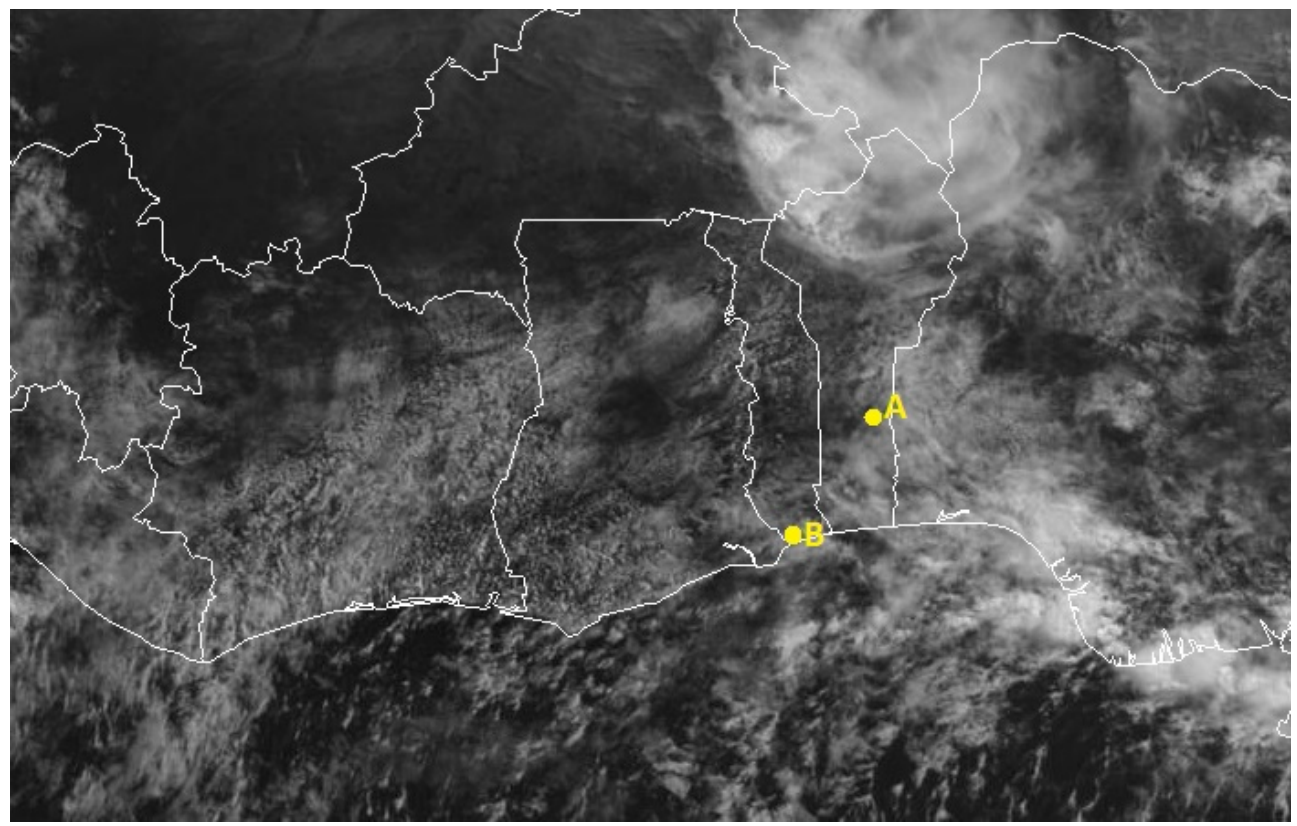

Figure 1. Image from the $0.6 \mu$ visible channel of the Meteosat-10 geostationary satellite, revealing the cloud structure over southern West Africa at 10:12 UTC on 5 July 2016. Borders and coastlines are highlighted, along with the locations of Savé and Lomé, labelled "A" and "B" respectively. Image obtained from http://catalogue.ceda.ac.uk/uuid/5fa2529b973e47ae38ab3557f2018ef4 (link valid as of July 2018).

ers (Derrien et al., 2016), radars and ceilometers (Handwerker et al., 2016), and microwave radiometers (Wieser et al., 2016). These ground-based observations were complemented by in situ measurements of aerosol and cloud properties from three European aircraft, which together conducted 50 research flights between 27 June and 16 July. The results presented in Kalthoff et al. (2018) reveal significant variability in the onset and dissolution of LLCs over SWA from day to day and from site to site. However the governing processes and mechanisms responsible are not fully understood. Furthermore, large-scale models struggle to represent these LLCs and their variability accurately. Hannak et al. (2017) found that many current general circulation models (GCMs) suffer a common bias in the form of insufficient low cloud cover over SWA, abundant solar radiation, and thus too large a diurnal cycle in temperature and relative humidity. They concluded that targeted model sensitivity experiments are needed to test possible feedback mechanisms among low clouds, radiation, BL dynamics, precipitation, and the WAM circulation.

Several studies have proposed specific mechanisms relevant for the formation and break-up of the cloud decks (e.g. Schrage and Fink, 2012; Schuster et al., 2013; Adler et al., 2017). Specifically, LLCs are believed to be sensitive to temperature and moisture advection from the south (controlled by the strength of the low-level jet), vertical mixing of heat and moisture arising due to shear-generated turbulence, radiative cooling at cloud top, condensational heating, sub-cloud evaporation, orographic lifting, and lifting induced by gravity wave propagation. In addition to each of these processes, it is important to also consider the role of microphysics in the evolution of LLCs and the potential modification of the cloud properties via the interaction with aerosols (Knippertz et al., 2015a, b). The combination of ground-based and in situ measurements from DACCIWA offers a unique opportunity to explore the links among aerosols, microphysics, and the bulk cloud properties in SWA and to inform an appropriate level of parameterization for the representation of LLCs in regional and global models.

One particular microphysical process of interest is the role of droplet sedimentation - the gravitational settling of liquid droplets suspended within the cloud layer. Previous studies of non-drizzling marine stratocumulus have demonstrated that droplet sedimentation has a non-negligible impact on the evolution of liquid water path (LWP) (e.g. Ackerman et al., 2004; Bretherton et al., 2007). However the role of sedimentation in relation to low-level clouds over SWA has not yet been investigated in detail, despite the potential for changes in aerosol properties in the SWA region to modify the size distribution of cloud droplets (and in turn their sedimentation velocity). Hence the purpose of the present study is to perform large-eddy simulations of a selected DACCIWA case study to isolate the effects of droplet sedimentation and quantify its impact on the ability of the model to reproduce the observations. In doing so, the aim is to identify an optimum configuration for the parameterization of BL clouds over SWA. The rest of this paper is organised as follows. Section 2 presents details of the case study to be simulated; 

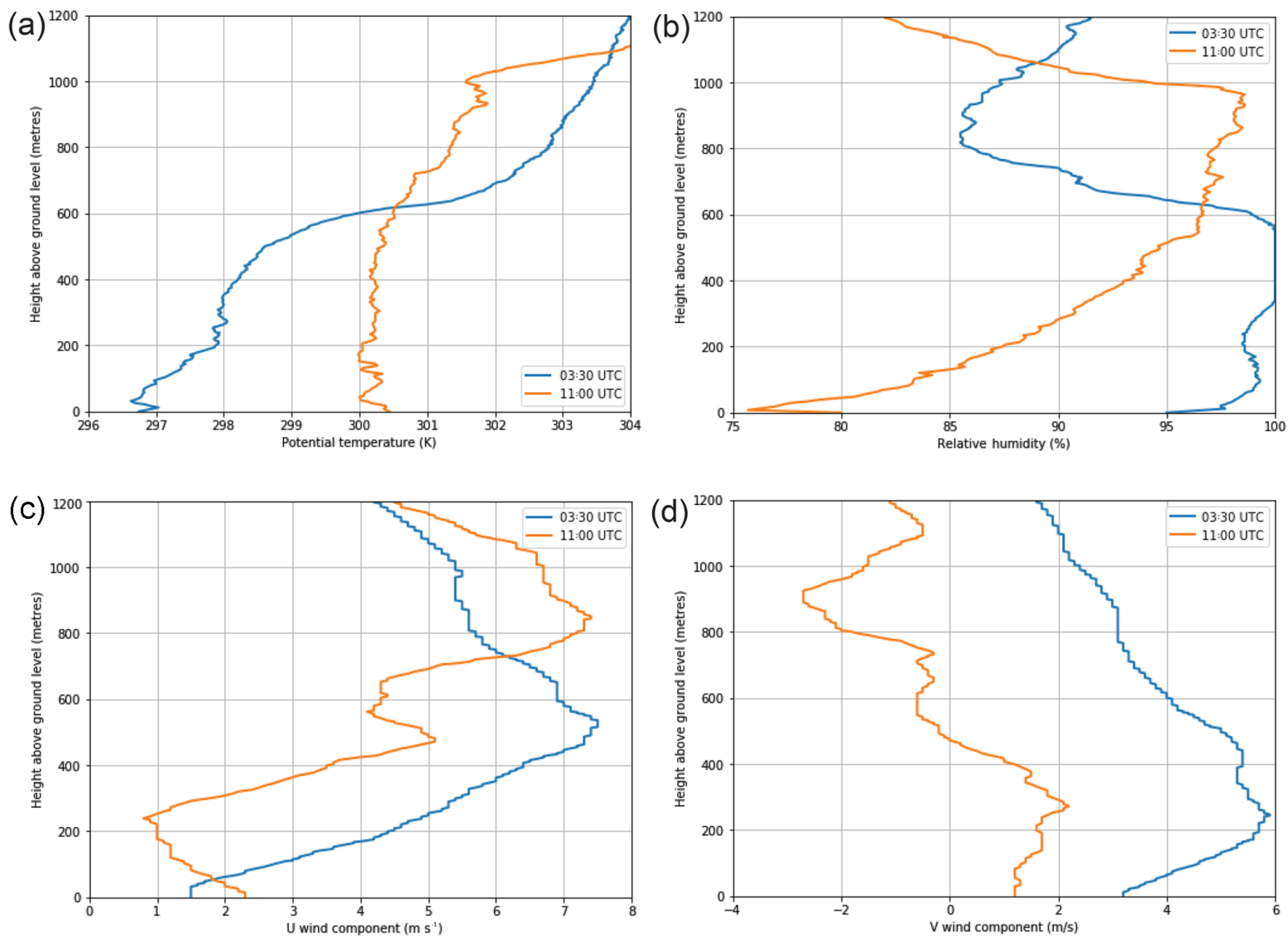

Figure 2. Profiles of (a) potential temperature, (b) relative humidity, (c) the $u$ wind component, and (d) the $v$ wind component from radiosondes launched at Savé on 5 July 2016 at 03:30 UTC (blue) and 11:00 UTC (orange).

Sect. 3 describes the numerical model used to perform the simulations, along with details regarding model configuration and initialisation, and the results are presented in Sect. 4. Implications of the findings are discussed in Sect. 5, before the main conclusions are summarised in Sect. 6.

\section{Case study}

For the purpose of this study, we focus on a particular case on 4-5 July 2016, the seventh intensive observation period (IOP) from the DACCIWA field campaign (Flamant et al., 2017). The satellite image in Fig. 1 reveals the extent of the cloud coverage over SWA at 10:12 UTC on 5 July 2016. The conditions were fairly typical of the campaign as a whole, with observations collected at the ground site at Savé (labelled "A" in Fig. 1) revealing the onset of the low-level jet around 18:00 UTC on 4 July, followed by the formation of a low-level stratocumulus deck during the night. Cloud at the Savé ground site was first observed at 03:00 UTC on 5 July, which persisted until around mid-day local time, after which it began to break up into patchy cumulus (see Flamant et al., 2017, their Fig. 6). No precipitation was recorded at the Savé ground site for this case, consistent with the majority of days sampled during the campaign period. For an overview of the diurnal cycle of the atmospheric BL at Savé during DACCIWA, the reader is referred to Kalthoff et al. (2018).

The radiosonde data from IOP 7 provide more information on the structure and evolution of the BL on this day. Profiles of potential temperature and relative humidity from the 03:30 UTC sonde, launched approximately half an hour after the cloud was first detected at Savé, are shown in Fig. 2a, b. The relative humidity profile reveals a cloud layer approximately $200 \mathrm{~m}$ thick, with a cloud top height of $550 \mathrm{~m}$ capped by a temperature inversion of $1.5 \mathrm{~K}$. The horizontal wind components, shown separately in Fig. 2c, d, reveal a low-level jet with a wind speed maximum at a height of $550 \mathrm{~m}$ a.g.l., and the cloud layer located directly beneath. Later sondes from 05:00, 06:28, 08:00, and 09:28 UTC (not shown) reveal that the cloud layer persisted throughout the morning, with the relative humidity occasionally peaking just below water saturation, suggesting the presence of some breaks in the cloud cover. This is consistent with images from the infrared camera at Savé (see Fig. 3), further analysis of which is presented in Dione et al. (2018) over the whole 
(a) 07:54 UTC
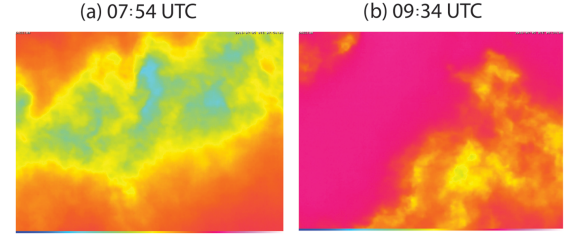

Figure 3. Images from the infrared cloud camera at Savé on 5 July 2016 (Derrien et al., 2016) for the times indicated. The images from the camera are coded in RGB colours (red, green, and blue), providing a qualitative estimate of cloud cover during the day and night. The image colour is dependent on the emissivity of the sky and consequently on the brightness temperature, such that red indicates warm and blue cold.

campaign period. The low-level jet persisted until around 11:00 UTC (Fig. 4a), by which time the depth of the BL had increased to $1 \mathrm{~km}$ due to solar heating of the surface, resulting in lifting of the cloud deck (as shown in Fig. 2a, b). Three research aircraft were also deployed in sequence on this day, taking in situ measurements along the transect between Lomé (labelled "B" in Fig. 1) and Savé from 08:00 UTC through to 18:00 UTC in order to sample the microphysical evolution during the cloud life cycle (Flamant et al., 2017).

\section{Model description}

To fulfill the needs of this study we utilise the Met Office NERC Cloud model (MONC; Brown et al., 2015). MONC is a rewrite of the original Met Office Large Eddy Model (LEM), which has been used extensively over the past 20 years to study cloud processes in a variety of regimes (e.g. Brown, 1999; Brown et al., 2002; Clark et al., 2005; Connolly et al., 2006, 2013; Marsham et al., 2006; Young et al., 2017). MONC offers several key advantages over the original LEM, including code optimisations, bug fixes, and a new solver that enables simulations to be performed with relatively large domain sizes without having to compromise on the model resolution.

Radiation is represented in MONC by the Suite of Community RAdiative Transfer codes based on Edwards and Slingo (SOCRATES; Edwards and Slingo, 1996), the same as that used in the Met Office Unified Model, specifically the Global Atmosphere Model 6.0 (Walters et al., 2017). SOCRATES is called on a 3 min time step, allowing the effects of longwave cloud top cooling and shortwave absorption within the cloud layer to be captured in the model.

Regarding the treatment of cloud processes, MONC is coupled to the CASIM (Cloud AeroSol Interactive Microphysics) module, a newly developed user-configurable multi-moment scheme that represents five hydrometeor species (cloud, rain, ice, snow, and graupel) and multi-mode aerosols. CASIM has already been used within the Met Office Unified Model to study aerosol-cloud interactions in different meteorological contexts, e.g. Grosvenor et al. (2017), Miltenberger et al. (2018), and Stevens et al. (2018). Further details on the specific configuration of CASIM used in the present study are given in Sect. 3.2.

\subsection{Model initialisation and configuration}

MONC is initialised using profiles of potential temperature, total water mass mixing ratio, and horizontal wind components, which are obtained from radiosondes launched from the Savé ground site. For IOP 7, we initialise the model using data from the 03:30 UTC radiosonde as shown in Fig. 2, interpolating the data onto the model grid with a vertical resolution of $10 \mathrm{~m}$. Where the initial relative humidity profile is at water saturation (i.e. between 350 and $550 \mathrm{~m}$ in Fig. 2b), the cloud liquid water mass mixing ratio profile is calculated assuming an adiabatic cloud parcel ascent from cloud base to cloud top. The profile of total water mass mixing ratio is then calculated as the sum of the cloud liquid water and water vapour mass mixing ratios at each model level. During the first model time step, this supersaturated profile results in the immediate production of a cloud layer via condensation and at an early enough stage in its life cycle to study its subsequent evolution over a period of $7.5 \mathrm{~h}$. The choice of the 03:30 UTC sonde for initialisation is justified since the aim of the present study is to focus on the role of microphysical factors that control the subsequent evolution of the LLC, rather than the meteorological factors that govern the onset of cloud formation.

Regarding the forcing of the wind field, the winds from 03:30 UTC are relaxed towards the $u$ and $v$ wind components from the 11:00 UTC radiosonde (as shown in Fig. 2c, d) over a period of $7.5 \mathrm{~h}$. This allows the model to maintain the low-level jet throughout the simulation period. No forcing increments are applied to either the potential temperature field or the moisture fields; however a constant largescale divergence of $5 \times 10^{-6} \mathrm{~s}^{-1}$ is imposed throughout the model domain to produce a constant large-scale subsidence. According to the ERA-Interim reanalysis dataset (Dee et al., 2011), this value lies within the variability range over SWA during the time period of the DACCIWA field campaign.

Importantly, MONC is not coupled to an interactive land surface scheme in the present study and so to represent the effects of the surface, time-varying fluxes of sensible and latent heat are prescribed using surface measurements from the Savé ground site (Kohler et al., 2016). Fluxes from 5 July 2016 used to force the model are plotted in Fig. 4b for the simulation period indicated.

All the simulations presented in this paper use a domain size of $7.5 \mathrm{~km} \times 7.5 \mathrm{~km}$ in the horizontal with a $30 \mathrm{~m}$ grid spacing and a vertical extent of $2 \mathrm{~km}$ with a $10 \mathrm{~m}$ spacing between vertical levels up to $1.5 \mathrm{~km}$, increasing to a $20 \mathrm{~m}$ spacing between $1.5 \mathrm{~km}$ and $2 \mathrm{~km}$. The top $500 \mathrm{~m}$ is a damping layer to prevent unwanted gravity waves from reflecting off the rigid model lid. The first 90 min of each simulation 
(a)

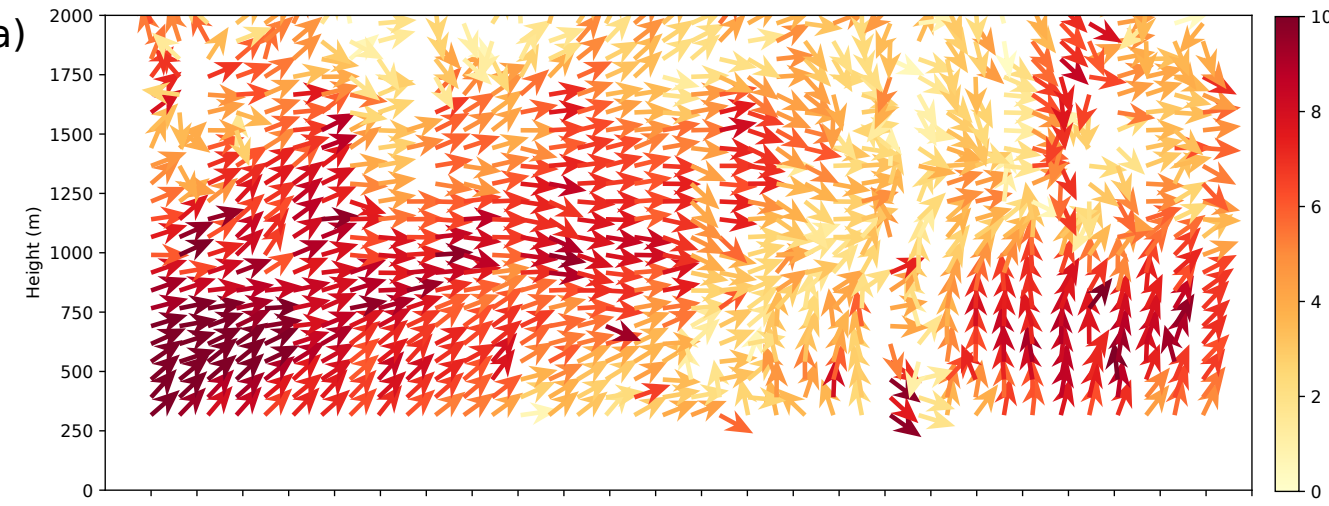

(b)

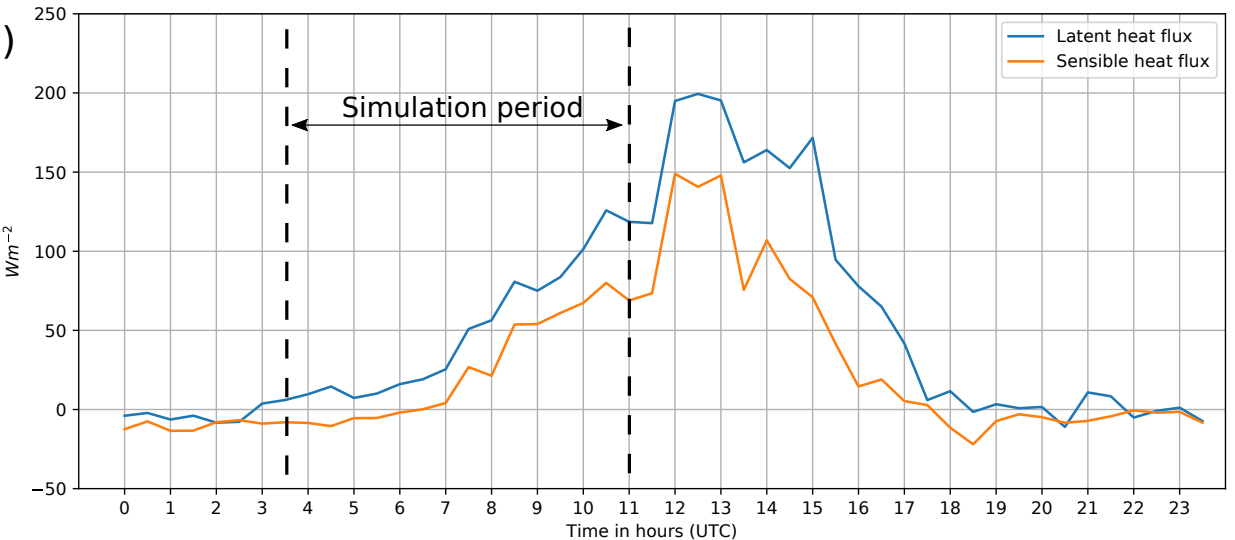

Figure 4. (a) Time-height plot showing the vertical profile of the horizontal wind at Savé on 5 July 2016, from the ultra-high-frequency wind profiler (Derrien et al., 2016). Wind vectors are normalised and indicate the direction of the horizontal flow; shading indicates the wind speed $\left(\mathrm{m} \mathrm{s}^{-1}\right)$. (b) Time series of latent heat flux (blue) and sensible heat flux (orange) from the Savé ground site on 5 July 2016 (Kohler et al., 2016).

(between 03:30 and 05:00 UTC) are discarded to allow the model to spin up from the initial conditions, and periodic boundary conditions are used in all cases.

\subsection{Details of model experiments}

Here we introduce and describe two initial experiments, the results from which are analysed in the next section.

The first MONC experiment with CASIM is configured for dual moment cloud and rain, while cold processes were not considered or required. Autoconversion and accretion are represented using the scheme of Khairoutdinov and Kogan (2000) and sedimentation of cloud droplets and rain is included. A saturation adjustment scheme is employed for condensation and evaporation of cloud droplets, while rain evaporation is based on the scheme used in the LEM (Gray et al., 2001). CASIM includes various options for aerosol activation and in this work we employ the scheme of AbdulRazzak et al. (1998), with the aerosol specified as a single accumulation mode log-normal size distribution following the analysis of regional aerosol properties in Haslett et al. (in preparation, 2018). The aerosol mass and number fields are completely passive in this experiment (i.e. not influenced by cloud and rain processes) and are used only to determine the number of droplets activated. This experiment is henceforth referred to as CASIM_NO_PROC.

The second MONC experiment is identical to CASIM_NO_PROC, the only difference being that droplet sedimentation is turned off following the $90 \mathrm{~min}$ spin-up period to allow turbulence to develop within the BL. We refer to this experiment as CASIM_NO_SED. The rationale of this second experiment is to explore whether a simulation with sedimentation disabled is able to reproduce the observations for this case and therefore to reveal the extent to which sedimentation impacts the simulation.

\section{Results}

We begin with an initial inspection of results from the CASIM_NO_PROC experiment. Figure 5a shows a timeheight plot of the domain-average cloud mass mixing ratio for the period 05:00-11:00 UTC. The presence of a cloud layer is revealed with an initial mean cloud base around $350 \mathrm{~m}$ and a cloud top of $600 \mathrm{~m}$. Following sunrise at 05:37 UTC, the surface fluxes of sensible and latent heat 

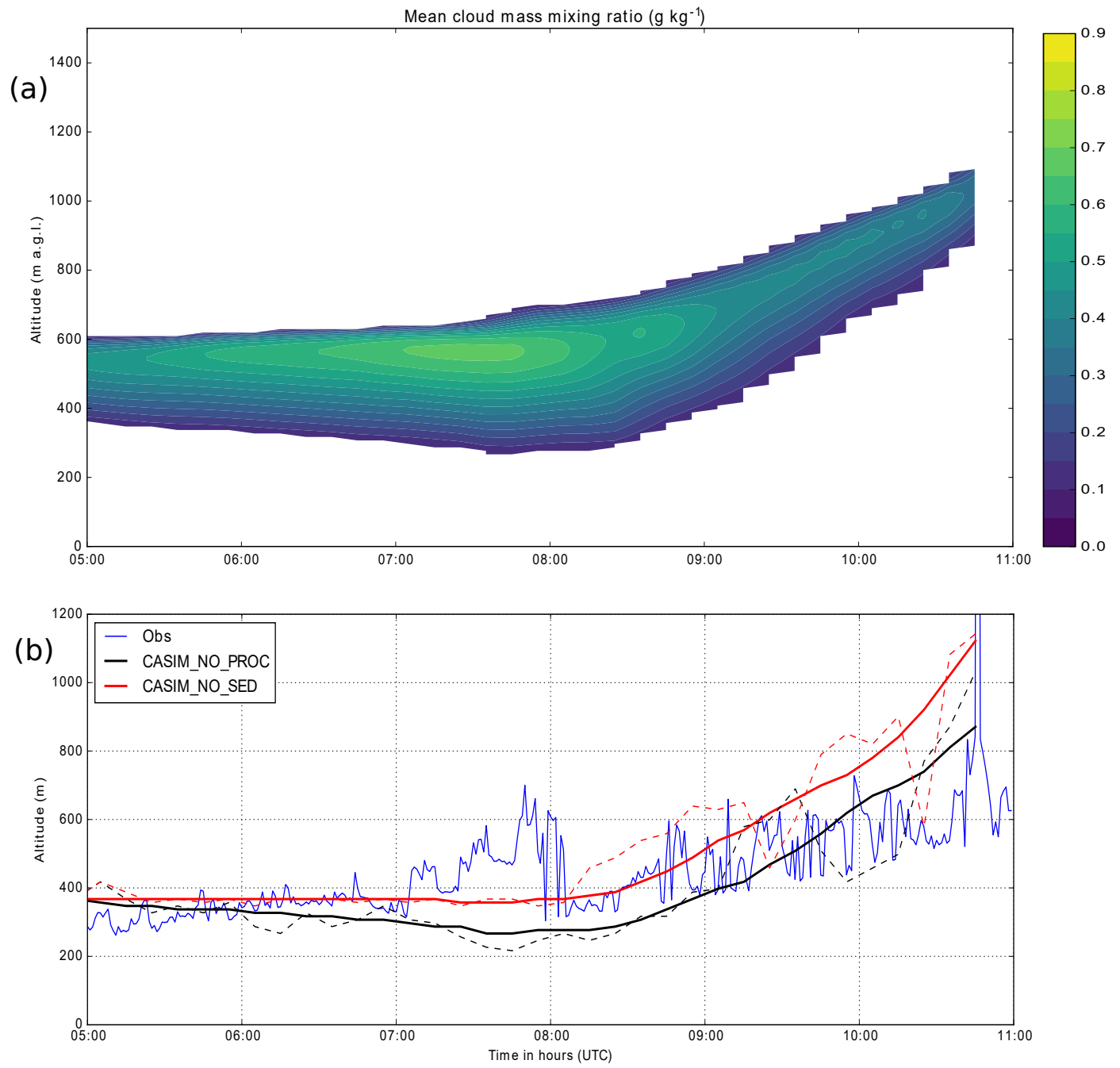

Figure 5. (a) Time-height plot of the mean cloud mass mixing ratio $\left(\mathrm{g} \mathrm{kg}^{-1}\right)$ within the model domain from the CASIM_NO_PROC experiment. Values are calculated as temporal means every $10 \mathrm{~min}$. (b) Time series of cloud base height at Savé on 5 July 2016 (blue) derived from ceilometer measurements (Handwerker et al., 2016), and cloud base height diagnosed from CASIM_NO_PROC and CASIM_NO_SED using a threshold cloud liquid water mass mixing ratio of $0.1 \mathrm{~g} \mathrm{~kg}^{-1}$. Solid black and red lines are the domain mean value; dashed black and red lines are the value at the centre of the model domain.

increase sharply from around 07:00 UTC as shown in Fig. 4b, resulting in a deeper BL and lifting of the cloud layer from around 08:00 UTC. The general trend in the time series of cloud base height is well captured by the model, as seen in the comparison against the ceilometer measurements from the Savé ground site (Fig. 5b). Cloud top longwave radiative cooling was found to be crucial for the development and maintenance of the cloud, through the generation of an overturning circulation within the cloud layer. Indeed, without any longwave cooling, the model was unable to sustain the cloud layer, resulting in complete dissipation by the end of the spin-up period.

Figure 6 provides further information about the evolution of the mixing state of the simulated BL, in terms of pro- files of liquid water potential temperature, liquid water mixing ratio, and total water mixing ratio following the diagnostic analysis of Jones et al. (2011). Domain-average profiles from 05:30 UTC (Fig. 6a) reveal a predominantly wellmixed cloud-topped BL capped by a temperature inversion at $600 \mathrm{~m}$ a.g.l. A stable layer exists from the surface up to $150 \mathrm{~m}$ a.g.l., consistent with longwave cooling of the surface during the night, with a thin fog layer which dissipates by 06:30 UTC. By 11:00 UTC (Fig. 6b), the increase in surface fluxes produces a deeper, convective BL with an unstable layer at the surface. A well-mixed layer exists between 50 and $400 \mathrm{~m}$ a.g.l. in the sub-cloud region, with a hint of a second shallower well-mixed layer directly below the top of the $\mathrm{BL}$, where the values of liquid water mixing ratio are largest. 
(a)

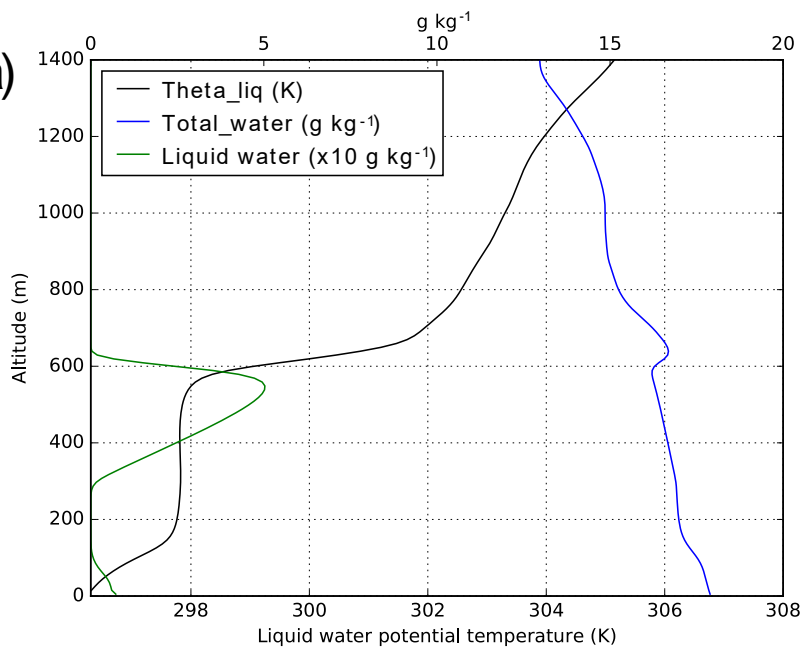

(c)

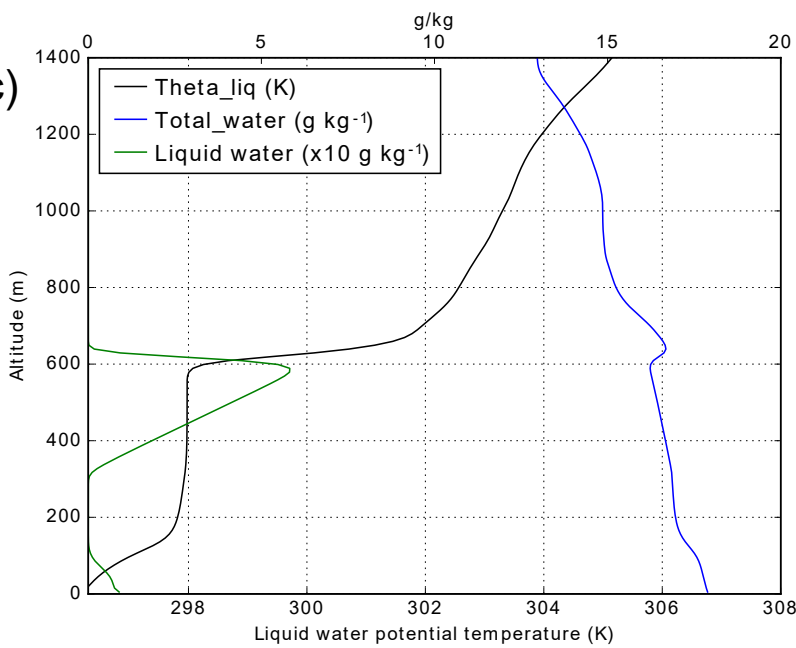

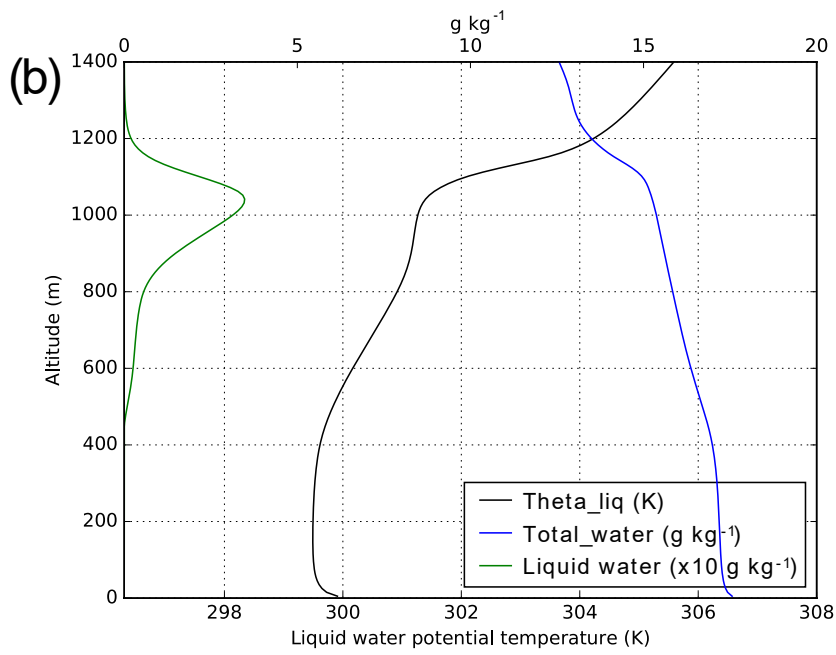

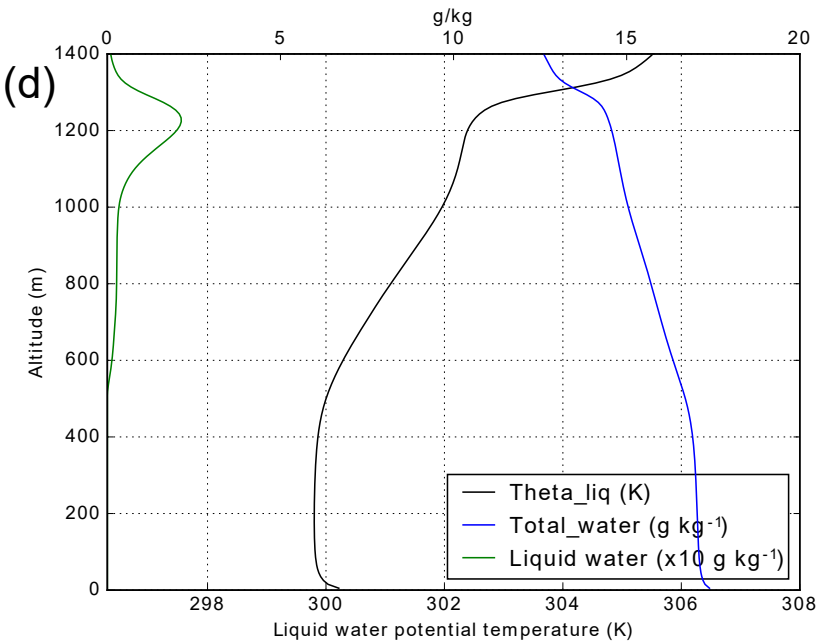

Figure 6. Vertical profiles of liquid water potential temperature (K; black lines), total water mass mixing ratio ( $\mathrm{g} \mathrm{kg}^{-1}$; blue lines), and liquid water mass mixing ratio $\left(\times 10 \mathrm{~g} \mathrm{~kg}^{-1}\right.$; green lines $)$ diagnosed at (a) 05:30 UTC and (b) 11:00 UTC from the CASIM_NO_PROC experiment. Equivalent plots for CASIM_NO_SED are shown in (c) and (d) respectively.

These layers are separated by a transition region between 400 and $900 \mathrm{~m}$ a.g.l., where the liquid water potential temperature gradually increases with height. Figure $7 \mathrm{a}$ and $\mathrm{b}$ show that the model captures the general deepening of the $\mathrm{BL}$ as seen in the observations, with a simulated BL height of $1.1 \mathrm{~km}$ by 11:00 UTC compared with $1 \mathrm{~km}$ in the corresponding radiosonde profile. The vertical structure of both potential temperature and relative humidity is also reasonably well captured by the model.

Figure 8a compares the time series of simulated LWP from CASIM_NO_PROC with observations from the vertically pointing ground-based microwave radiometer at Savé (Wieser et al., 2016). Because the radiometer measurements represent the time evolution at a single location, care must be taken when evaluating the model against this dataset to account for the difference in spatial sampling. Hence in
Fig. 8 we plot both the simulated LWP time series taken from the centre of the model domain diagnosed at 1 min intervals, together with the variability in LWP across the whole domain. The model simulates the evolution of LWP in a manner that is broadly consistent with the measurements, with the observations for the most part lying within \pm 2 standard deviations of the simulated LWP values. Peak local values of LWP also occur at approximately the correct time in the model, i.e. after 08:00 UTC when the surface fluxes have started to rise sharply. No precipitation was produced by the model during the simulation period, consistent with the measurements at Savé.

Having validated the ability of CASIM_NO_PROC to capture the key features of the observations, we now consider the impact of disabling sedimentation by analysing results from the CASIM_NO_SED experiment. Figure 8b 

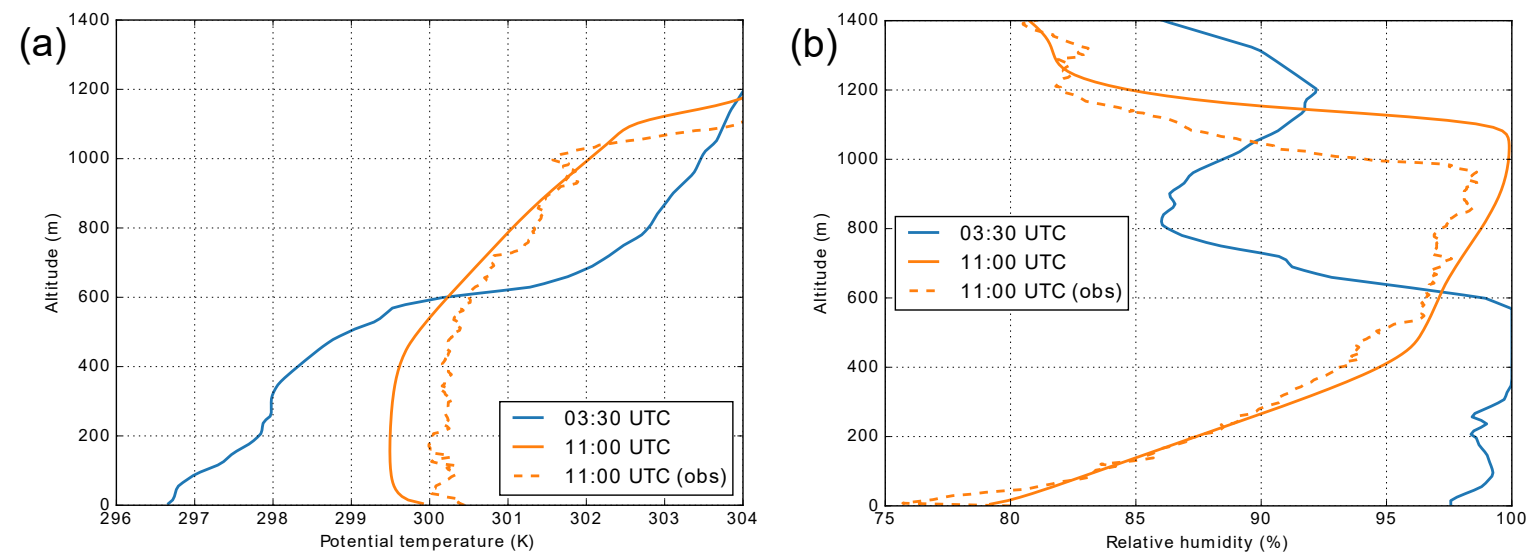

Figure 7. Simulated domain-average vertical profiles of (a) potential temperature and (b) relative humidity from the CASIM_NO_PROC simulation, calculated at 03:30 UTC (blue) and 11:00 UTC (orange). In each case the dashed orange line corresponds to the radiosonde profile from 11:00 UTC.

shows that CASIM_NO_SED underestimates the variability in LWP before 07:30 UTC compared to both the observations and CASIM_NO_PROC. Maps comparing the spatial distribution of LWP within the model domain for both simulations (Fig. 9) confirm that the cloud is much more spatially homogeneous in CASIM_NO_SED initially, resembling a largely featureless sheet of stratus as opposed to the more lumpy stratocumulus seen in CASIM_NO_PROC. A comparison of the time series of mean LWP in the domain (solid lines in Fig. 10) reveals that, although both simulations show a similar rise and fall pattern with a peak around mid-morning, there are still some notable differences despite neither simulation producing any precipitation. For instance, following completion of the spin-up phase at 05:00 UTC, the rate of LWP growth slows in CASIM_NO_SED relative to CASIM_NO_PROC such that by 07:00UTC, CASIM_NO_PROC has the higher LWP. The peak LWP in CASIM_NO_SED occurs around the same time but persists for longer, before decreasing sharply around 10:00 UTC. The other difference between the two simulations is in the evolution of the domain mean cloud base height. Figure $5 \mathrm{~b}$ shows that CASIM_NO_SED maintains an elevated cloud base height compared to CASIM_NO_PROC throughout the simulation period. Between 05:30 and 08:00 UTC, the mean cloud base height is $60 \mathrm{~m}$ higher in CASIM_NO_SED, increasing to an average of $140 \mathrm{~m}$ higher between 08:00 and 11:00 UTC.

The link between droplet sedimentation and LWP has been explored previously by Bretherton et al. (2007) in the context of nocturnal non-drizzling marine stratocumulus layers in the subtropics. Sedimentation was found to ultimately increase LWP, caused by the removal of liquid water from the entrainment zone near cloud top. In turn this reduces the magnitudes of evaporative cooling and longwave radiative cooling, two processes which control the sinking of relatively dry air from the free troposphere into the cloud layer. Conversely, higher cloud condensation nuclei concentrations decrease the mean droplet size and fall speed, reducing sedimentation rates and thus making the cloud more susceptible to the effects of entrainment at the top of the BL. This results in a reduced LWP and a thinner cloud layer for more polluted conditions. We now conduct further analysis of the two MONC experiments to explore whether the results of the present study are consistent with the findings of Bretherton et al. (2007).

Returning to Fig. 10, following completion of the spinup phase at 05:00 UTC, both simulations have the same value of LWP. As mentioned earlier, the initial development of the cloud layer during the spin-up phase is strongly dependent on the mechanism of longwave radiative cooling. By 05:30 UTC, the lack of droplet sedimentation in CASIM_NO_SED means that this experiment is able to maintain a slightly higher liquid water content at cloud top relative to CASIM_NO_PROC, with a more sharply defined peak value (see Fig. 6c compared to Fig. 6a). Over the following $1.5 \mathrm{~h}$, the larger liquid water content within the entrainment zone in CASIM_NO_SED promotes stronger evaporative cooling and longwave radiative cooling relative to CASIM_NO_PROC (see Fig. 11). This increases the downward heat flux at cloud top, reduces moisture fluxes, and reduces the circulation strength in the BL (Fig. 12). The result is a slower rate of LWP growth with time relative to CASIM_NO_PROC, such that by 07:00 UTC, CASIM_NO_PROC has the higher LWP. Thus in CASIM_NO_PROC, the removal of liquid water mass from cloud top due to droplet sedimentation effectively acts to shield the cloud layer to some extent from the effects of entrainment, allowing LWP to grow faster with time.

A closer inspection of Fig. 11 reveals more information about the relative roles of radiative cooling and evaporative cooling in the evolution of the cloud layer. In both simula- 

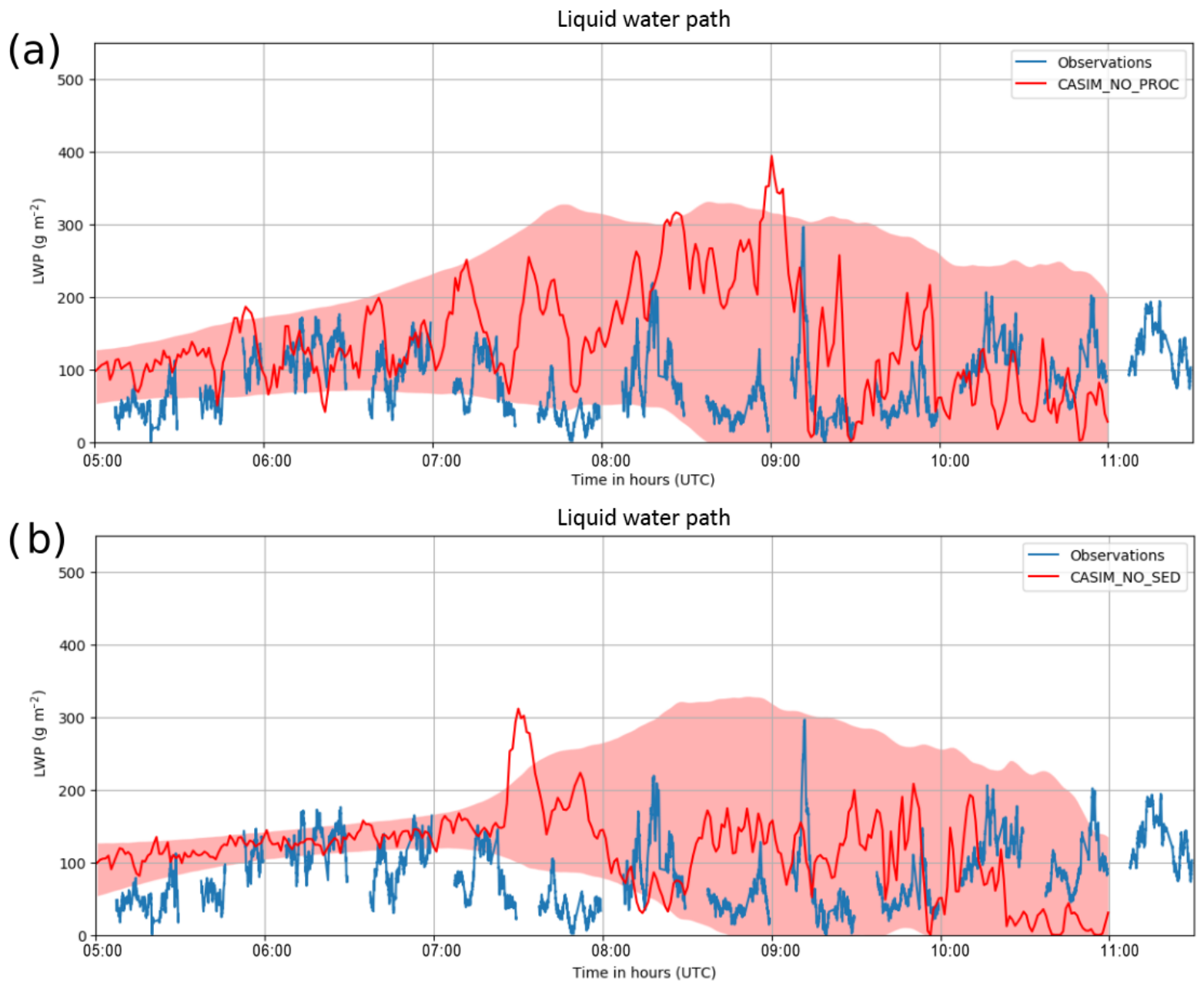

Figure 8. (a) Comparison of LWP time series at Savé from 5 July 2016 (blue) as measured by the microwave radiometer (Wieser et al., 2016), with simulated LWP from CASIM_NO_PROC, showing the evolution of LWP at the centre of the model domain (red line) and the LWP variability within the whole domain (red shading), expressed as \pm 2 standard deviations from the domain mean value. Panel (b) as (a) but for CASIM_NO_SED.

tions, it is clear that radiative cooling is the dominant process, with peak rates that are typically an order of magnitude larger than those produced by evaporation near cloud top. The absence of sedimentation in CASIM_NO_SED results in larger cooling rates associated with both processes. However, the increase in longwave cooling rates is relatively modest around $37 \%$ by 07:00 UTC - whereas evaporative cooling rates increase by a factor of 2 within the same time period. Thus in relative terms, the effect of sedimentation appears to have the largest impact on rates of evaporative cooling.

It is important to remember that the present study is over land and the simulation period extends into the daytime, as opposed to the nocturnal marine BL simulated by Bretherton et al. (2007). Thus it is no surprise that after 08:00 UTC, when the fluxes of sensible and latent heat dominate and the surface layer becomes unstable, the effect of sedimen- tation on LWP starts to break down. The convective vertical mixing associated with the prescribed sensible and latent heat fluxes coincides with the lifting of the cloud layer and a decrease in LWP, with a more rapid depletion evident in CASIM_NO_PROC (Fig. 10). This is consistent with stronger evaporative cooling during mixing associated with the higher LWP around 07:30 UTC.

It is interesting to consider what would happen to the evolution of LWP in the absence of surface-driven mixing. This is important because, although the mean LLC onset time at Savé is 03:00 UTC (around $3 \mathrm{~h}$ before sunrise), it is notably earlier at other ground sites (e.g. 00:00 UTC in Kumasi, and 21:00 UTC at Ile-Ife; Kalthoff et al., 2018). Assuming the sedimentation-entrainment feedback holds true, an earlier LLC onset would allow more time for the effects of sedimentation to impact LWP before sunrise. To 

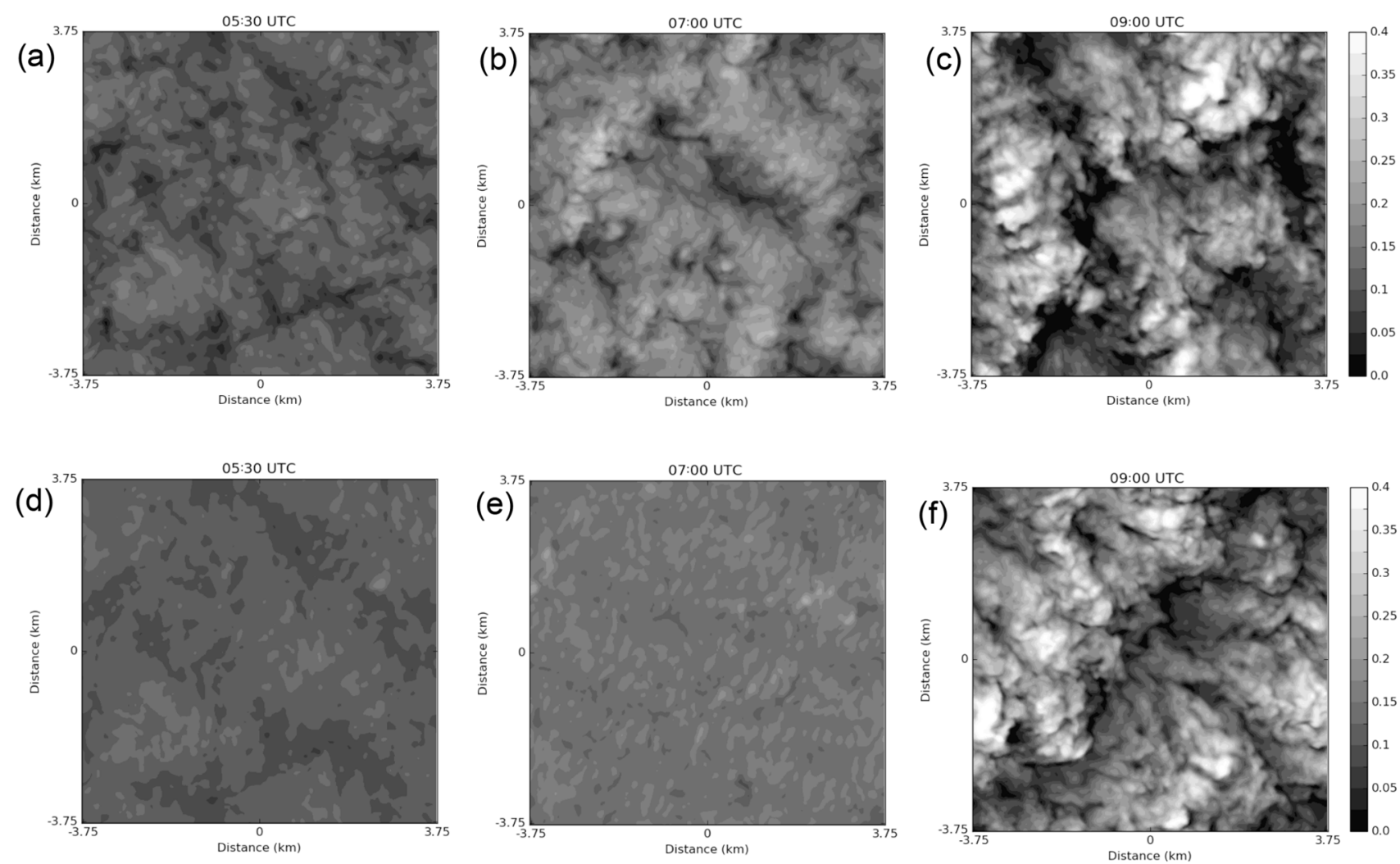

Figure 9. Maps showing the spatial distribution of LWP $\left(\mathrm{kg} \mathrm{m}^{-2}\right)$ within the model domain at 05:30, 07:00, and 09:00 UTC for CASIM_NO_PROC $(\mathbf{a}-\mathbf{c})$ and CASIM_NO_SED $(\mathbf{d}-\mathbf{f})$.

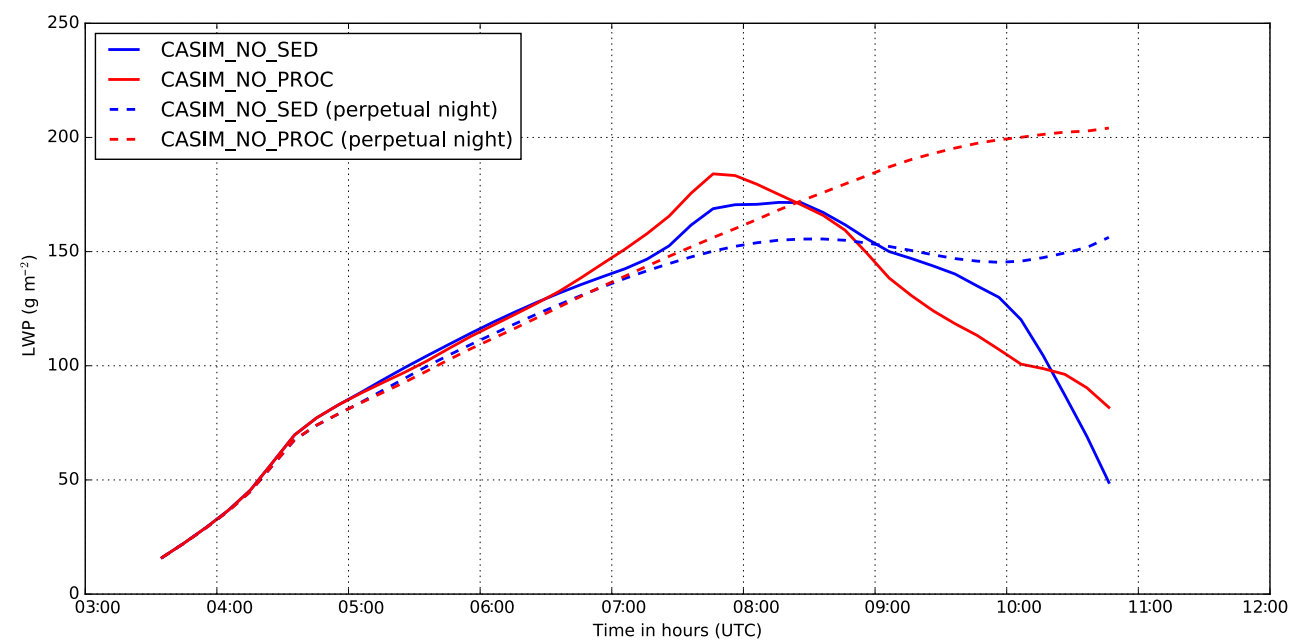

Figure 10. Time series of simulated LWP $\left(\mathrm{g} \mathrm{m}^{-2}\right)$ from CASIM_NO_PROC (solid red line) and CASIM_NO_SED (solid blue line). Dashed lines show results from "perpetual night" simulations, i.e. with shortwave radiation disabled and surface fluxes set to zero throughout the simulation period. In each case, LWP is calculated from $200 \mathrm{~m}$ to the top of the model domain in order to ignore the thin fog layer near the surface that develops during the spin-up period and dissipates around 06:30 UTC.

explore this idea, both experiments were rerun with surface fluxes set to zero throughout and with shortwave radiation turned off for the duration of the simulation. The forcing of the low-level jet was left unchanged. The results are shown as dashed lines in Fig. 10. As anticipated, it can clearly be seen that when nocturnal conditions are 

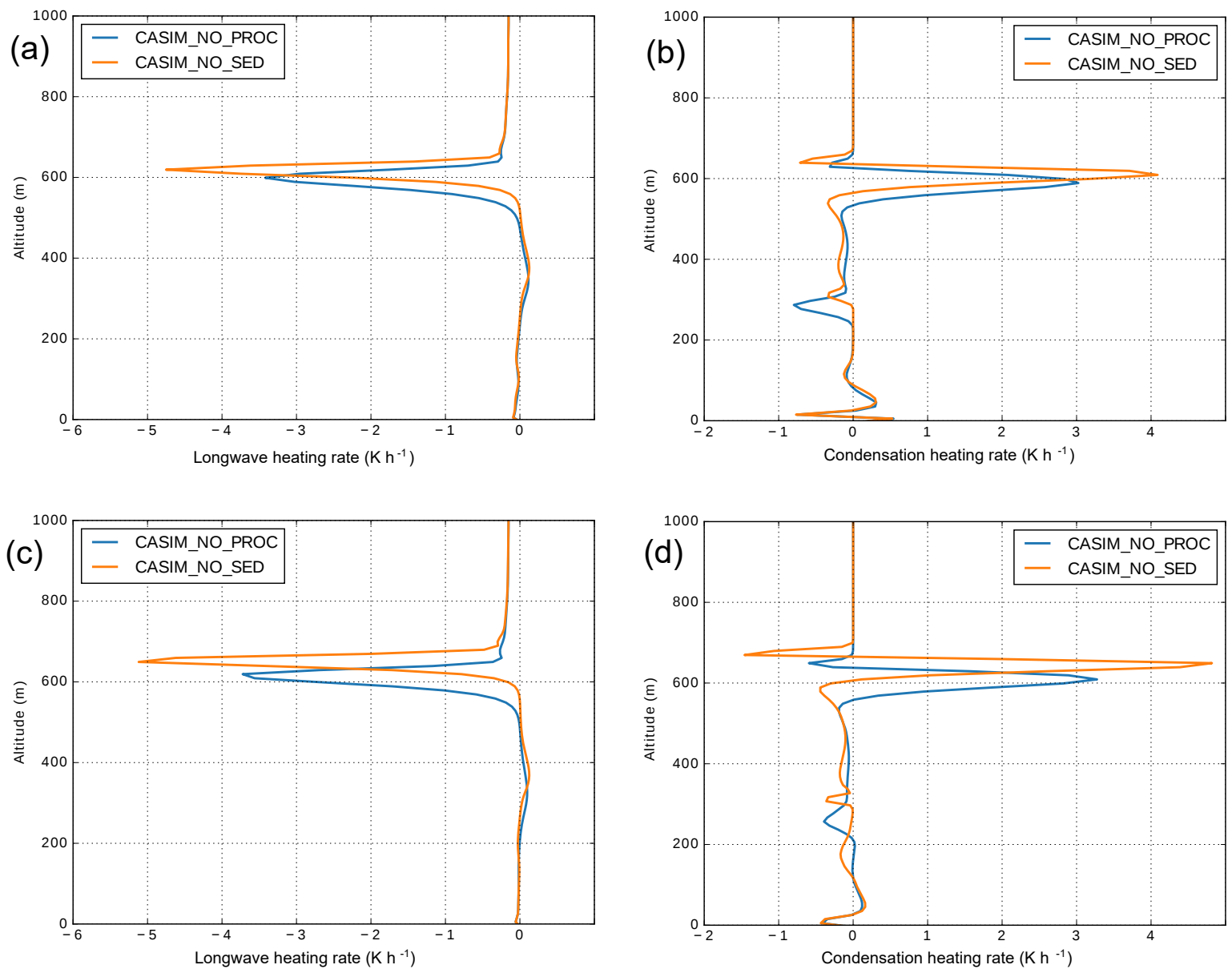

Figure 11. Domain-average vertical profiles of (a) longwave radiative heating rate $\left(\mathrm{Kh}^{-1}\right)$ and (b) condensation heating rate $\left(\mathrm{Kh} \mathrm{h}^{-1}\right)$ calculated as temporal means between 05:00 and 05:30 UTC for CASIM_NO_PROC (blue) and CASIM_NO_SED (orange). Longwave and condensation heating rates for the period 06:30-07:00 UTC are shown in (c) and (d) respectively.

maintained, CASIM_NO_PROC exhibits a higher LWP by around $33 \%$ relative to CASIM_NO_SED by the end of the simulation period. Based on this analysis, we conclude that the response of the model is consistent with the reasoning of Bretherton et al. (2007).

\section{Discussion}

The numerical experiments performed in this study have shown that droplet sedimentation helps to promote a more heterogeneous cloud layer, with localised regions of both enhanced LWP and reduced LWP within the model domain relative to simulations without droplet sedimentation, whilst also lowering cloud base height. Whilst surface fluxes remain relatively small, in this case prior to 07:00 UTC, sedimentation also acts to increase the rate of mean LWP growth within the domain by buffering the cloud layer from the effects of cloud top entrainment driven by evaporative cooling and longwave radiative cooling.
Since droplet sedimentation rates are inversely proportional to number concentration, one would expect the effects of sedimentation on both LWP and cloud base height to become more prominent as cloud droplet number concentration (CDNC) reduces. In the case of CASIM_NO_PROC, predicted number concentrations lie in the range of 400 $700 \mathrm{~cm}^{-3}$ at STP, which agrees well with in situ measurements with median values of around $500 \mathrm{~cm}^{-3}$ at STP (Jonathan Taylor, personal communication, 2018). In this section we perform some new experiments to explore the sensitivity to reducing CDNC. We introduce results from a new experiment, CASIM_200, which prescribes the initial CDNC to be $200 \mathrm{~cm}^{-3}$. This new simulation produces excessive variability in the LWP field and cloud bases that are too low (Figs. 13 and 14 respectively), confirming our hypothesis. This was found to be the case even with autoconversion switched off. The depth of the BL in CASIM_200 is also too shallow by the end of the simulation period, by virtue of the effect of increased droplet size and excessive 

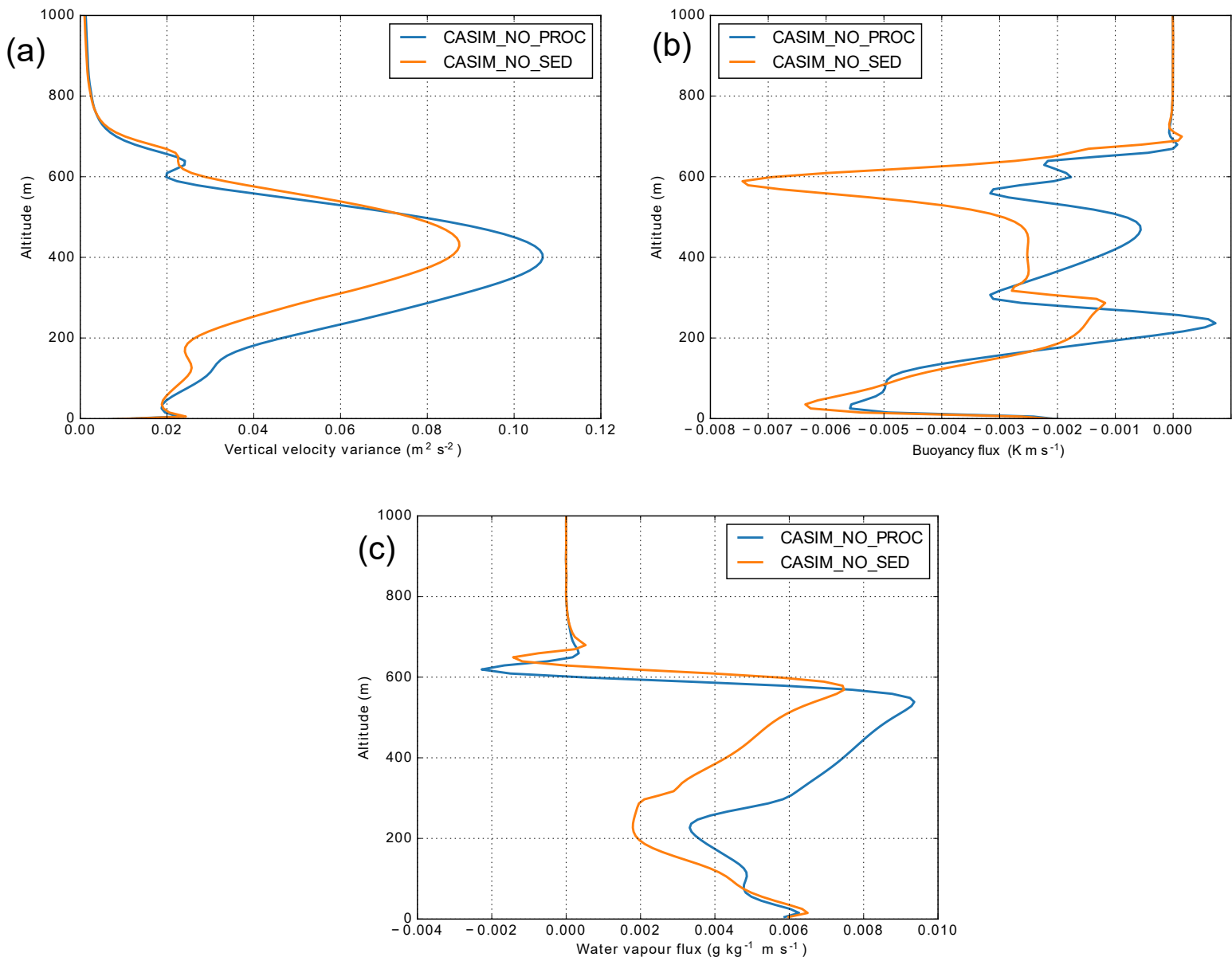

Figure 12. Domain-average vertical profiles of (a) vertical velocity variance $\left(\mathrm{m}^{2} \mathrm{~s}^{-2}\right)$, (b) buoyancy flux $\left(\mathrm{K} \mathrm{m} \mathrm{s}^{-1}\right)$, and (c) water vapour flux $\left(\mathrm{g} \mathrm{kg}^{-1} \mathrm{~m} \mathrm{~s}^{-1}\right)$, calculated as temporal means between 05:30 and 07:00 UTC for CASIM_NO_PROC (blue) and CASIM_NO_SED (orange).

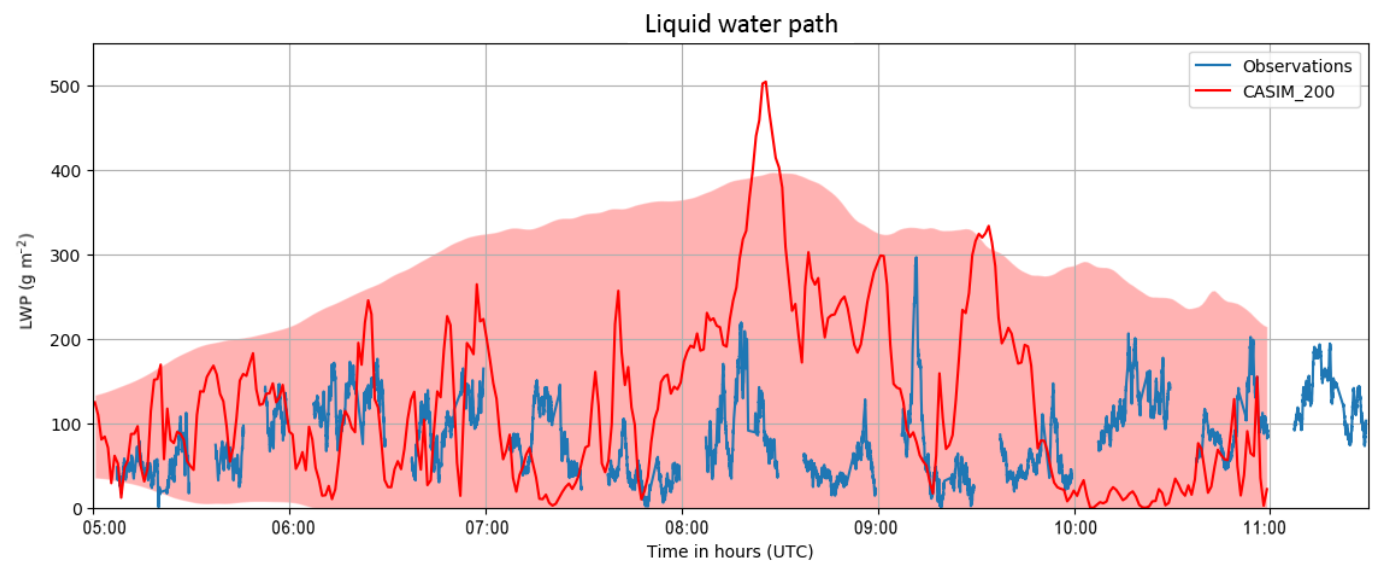

Figure 13. As in Fig. 8 but for CASIM_200.

sedimentation velocity on entrainment. However, mean LWP is slightly lower compared to CASIM_NO_PROC; this is because, around 08:30 UTC, cloud base becomes so low it touches the surface and liquid water is removed from the domain. At $200 \mathrm{~cm}^{-3}$, this removal of liquid is predominantly due to gravitational settling of cloud droplets as opposed 


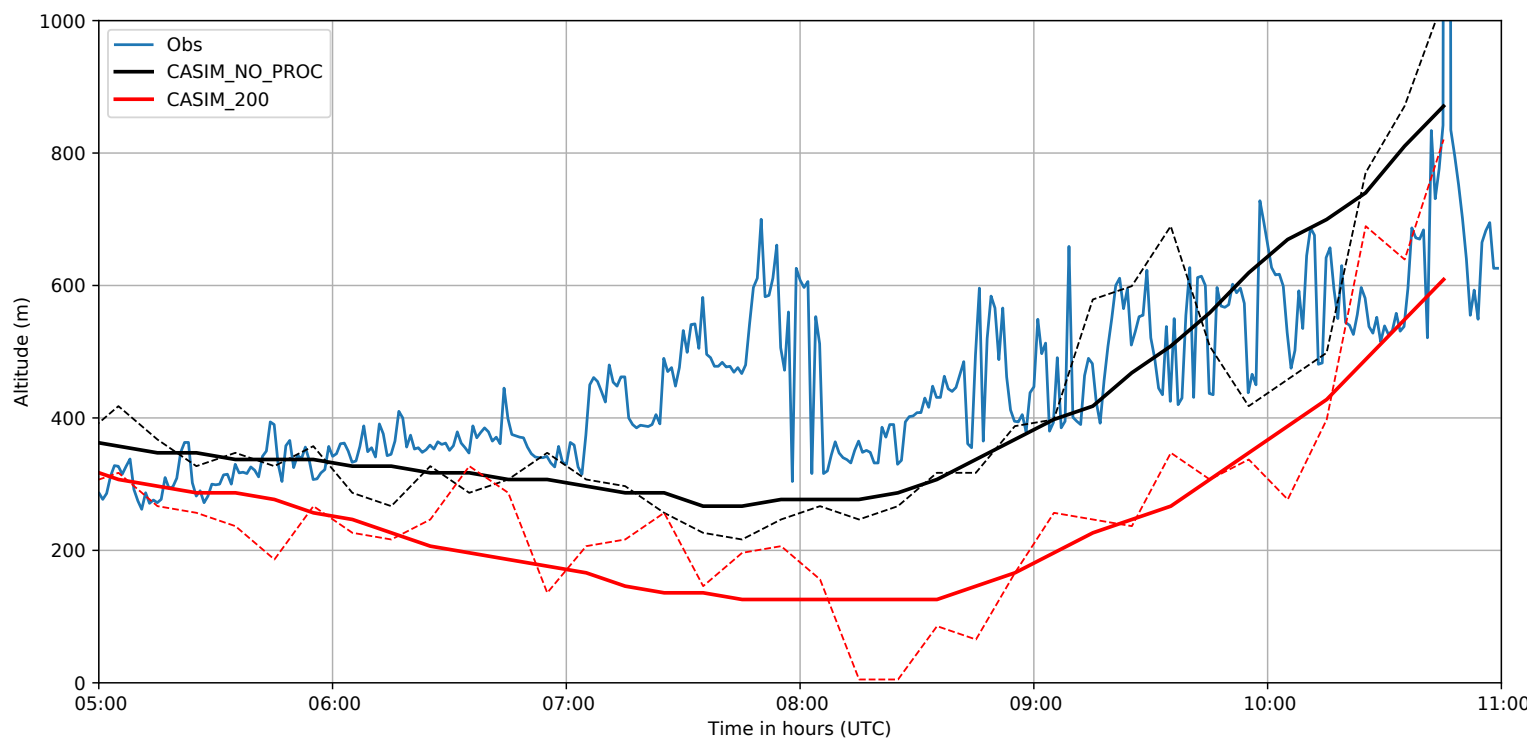

Figure 14. As in Fig. 5b but with results from CASIM_200 shown in red.

Table 1. Table showing the mean values of liquid water path (LWP: $\mathrm{g} \mathrm{m}^{-2}$ ), rain water path (RWP: $\mathrm{g} \mathrm{m}^{-2}$ ), and surface precipitation rate $\left(\mathrm{mm} \mathrm{h}^{-1}\right)$ calculated between 06:00-08:00 and 08:00-10:00 UTC for five different simulations, listed in order of increasing rates of droplet sedimentation achieved by reducing droplet number.

\begin{tabular}{lrrr|rrr}
\hline & \multicolumn{3}{c|}{ 06:00-08:00 UTC } & \multicolumn{3}{c}{$08: 00-10: 00$ UTC } \\
\cline { 2 - 7 } & LWP & RWP & Precip. rate & LWP & RWP & Precip. rate \\
\hline CASIM_NO_SED & 143.29 & 0 & 0 & 157.05 & 0 & 0 \\
CASIM_NO_PROC & 150.08 & 0.014 & 0 & 150.65 & 0.015 & 0 \\
CASIM_200 & 133.96 & 0.16 & 0.0015 & 129.50 & 0.17 & 0.0017 \\
CASIM_100 & 129.49 & 0.24 & 0.004 & 122.47 & 0.33 & 0.0069 \\
CASIM_50 & 90.58 & 0.44 & 0.025 & 83.29 & 0.59 & 0.015 \\
\hline
\end{tabular}

to significant warm rain production. Further reductions in CDNC, down to 100 and $50 \mathrm{~cm}^{-3}$, respectively, deplete the LWP even more as a result of an increase in autoconversion. These results, as summarised in Table 1, suggest that the effects of droplet size on cloud top entrainment rates should not be ignored when considering the diurnal cycle of LLCs in the region.

In light of this result, it is pertinent to consider the potential implications of changes in CDNC in terms of cloud radiative effects. Any elevation of CDNC within urban plumes will increase cloud optical depth in a manner that is proportional to $\mathrm{CDNC}^{1 / 3}$ and $\mathrm{LWP}^{2 / 3}$ for shallow clouds. However, the reduced sedimentation associated with the increased CDNC would increase cloud top entrainment and therefore reduce LWP. Hence any effect of increased optical thickness arising from enhanced aerosol concentrations will to some extent be offset by the sedimentation-entrainment feedback and is likely to lessen any first-order indirect effect.

Our findings also have implications for the diagnosis of aerosol-cloud interactions from satellite data. An adiabatic cloud profile is typically assumed when estimating cloud properties from satellites, but a relevant issue here is the extent to which the adiabatic assumption holds in these lowlevel clouds (Merk et al., 2016). Since satellites view cloud top, it is conceivable that the sedimentation-entrainment effect may well bias retrievals significantly.

An important caveat in our results is the prescription of surface fluxes in our simulations; there is no feedback among changes in cloud cover, LWP, and the land surface radiation budget. What happens after sunrise in reality is likely to be dependent on such feedbacks, which the present model configuration is not able to capture due to the lack of an interactive land surface scheme. Coupling of MONC to an interactive land surface scheme is needed to be able to comment fully on the impacts of droplet sedimentation and cloud optical depth on the diurnal cycle of these low-level clouds. 


\section{Conclusions}

In this study, large-eddy simulations of low-level clouds over southern West Africa have been performed with a focus on establishing the sensitivity of the cloud evolution to the treatment of droplet sedimentation. The simulations are constrained and validated using the unprecedented suite of measurements collected during the DACCIWA field campaign in 2016.

Our results reveal that, even for non-precipitating clouds, the evolution of low-level clouds over southern West Africa is sensitive to the effects of droplet sedimentation, suggesting that this mechanism should not be neglected when performing large-scale simulations of the region. Sedimentation of droplets acts to remove liquid water from the entrainment zone near cloud top, reducing the magnitude of evaporative cooling and longwave radiative cooling during entrainment mixing. This increases the rate of growth of liquid water path during the night-time and early morning period. For the conditions of prescribed subsidence and surface fluxes, the simulation best able to reproduce the observations was the one that came closest to matching the observed droplet number concentrations. Ignoring droplet sedimentation completely reduced variability in liquid water path by around a factor of 2 during the early morning and also elevated the mean cloud base height by an additional $200 \mathrm{~m}$ by the end of the simulation period. Conversely, overestimating sedimentation rates, by virtue of reducing the droplet number concentration by a factor of 2 or more relative to observed values, caused cloud base to lower to the surface by 08:30 UTC and liquid water path variability to increase by around a factor of 2 . Both these changes degraded the realism of the model simulation with respect to the available observations. In all cases, cloud top longwave radiative cooling during the night was found to be crucial for the formation and maintenance of the clouds.

The link between sedimentation and liquid water path has been noted previously in relation to nocturnal non-drizzling marine BL clouds. But the clouds considered in the present study form over land and persist into the daytime, which means that the effect of sedimentation can potentially play an important role in regulating the surface radiation budget, with consequences for the diurnal cycle of the BL in southern West Africa and possibly the circulation of the West African Monsoon. The results of our study suggest the possibility of a complex feedback chain involving aerosols, sedimentation, entrainment, liquid water path, and surface energy fluxes. We recommend as part of future work that the experiments performed in this study be repeated using an interactive land surface scheme to determine the extent to which the sensitivities shown are modified due to feedbacks between cloud cover and the surface heat flux budget.

Code and data availability. The observational data used in this paper can be accessed upon request at http://baobab.sedoo.fr/
DACCIWA (last access: 30 September 2018). The MONC, CASIM, and SOCRATES codes are maintained by the Met Office and accessible via the Met Office Science Repository Service (https://code. metoffice.gov.uk/) (last access: 30 September 2018). The MONC branch is available at https://code.metoffice.gov.uk/main/branches/ dev/chrisdearden/r4366_dacciwa_socrates_vn0.8_vn0.9_part2 (last access: 30 September 2018). The CASIM branch is available at https://code.metoffice.gov.uk/casim/branches/dev/chrisdearden/ r4323_casim_vn10.8_monc_fixes (last access: 30 September 2018).

For further details, please contact Christopher Dearden (c.dearden@leeds.ac.uk) or Adrian Hill (adrian.hill@metoffice.gov.uk).

Author contributions. CD was the primary author of the paper, and led the design of the numerical experiments and the subsequent analysis. AH provided essential development and technical support for the MONC model, and assisted in the experimental design. $\mathrm{AH}$, HCoe and TC all contributed to the analysis of the model results and the writing of the paper.

Competing interests. The authors declare that they have no conflict of interest.

Acknowledgements. The research leading to these results has received funding from the European Union 7th Framework Programme (FP7/2007-2013) under grant agreement no. 603502 (EU project DACCIWA: Dynamics-aerosol-chemistry-cloud interactions in West Africa). The authors would like to acknowledge Norbert Kalthoff, Bianca Adler, Karmen Babic, Fabienne Lohou, Cheikh Dione, Marie Lothon, and Xabier Pedruzo Bagazgoitia for their role in producing the observations presented in this paper and for helpful discussions at the DACCIWA project meeting in Karlsruhe, Germany, 24-27 October 2017. This work used the ARCHER UK National Supercomputing Service (http://www.archer.ac.uk (last access: 30 September 2018).) and the JASMIN service (http://www.jasmin.ac.uk (last access: 30 September 2018).).

Edited by: Susan van den Heever

Reviewed by: two anonymous referees

\section{References}

Abdou, K., Parker, D. J., Brooks, B., Kalthoff, N., and Lebel, T.: The diurnal cycle of lower boundary-layer wind in the West African monsoon, Q. J. Roy. Meteorol. Soc., 136, 66-76, https://doi.org/10.1002/qj.536, 2010.

Abdul-Razzak, H., Ghan, S. J., and Rivera-Carpio, C.: A parameterization of aerosol activation - 1. Single aerosol type, J. Geophys. Res.-Atmos., 103, 6123-6131, 1998.

Ackerman, A., Kirkpatrick, M. P., Stevens, D. E., and Toon, O. B.: The impact of humidity above stratiform clouds on indirect aerosol climate forcing, Nature, 432, 1014-1017, https://doi.org/10.1038/nature03174, 2004. 
Adler, B., Kalthoff, N., and Gantner, L.: Nocturnal low-level clouds over southern West Africa analysed using highresolution simulations, Atmos. Chem. Phys., 17, 899-910, https://doi.org/10.5194/acp-17-899-2017, 2017.

Bain, C. L., Parker, D. J., Taylor, C. M., Kergoat, L., and Guichard, F.: Observations of the Nocturnal Boundary Layer Associated with the West African Monsoon, Mon. Weather Rev., 138, 31423156, https://doi.org/10.1175/2010MWR3287.1, 2010.

Birch, C. E., Parker, D. J., Marsham, J. H., Copsey, D., and Garcia-Carreras, L.: A seamless assessment of the role of convection in the water cycle of the West African Monsoon, J. Geophys. Res.-Atmos., 119, 2890-2912, https://doi.org/10.1002/2013JD020887, 2014.

Bretherton, C. S., Blossey, P. N., and Uchida, J.: Cloud droplet sedimentation, entrainment efficiency, and subtropical stratocumulus albedo, Geophys. Res. Lett., 34, L03813, https://doi.org/10.1029/2006GL027648, 2007.

Brown, A.: The sensitivity of large-eddy simulations of shallow cumulus convection to resolution and subgrid model, Q. J. Roy. Meteor. Soc., 125, 469-482, https://doi.org/10.1002/qj.49712555405, 1999.

Brown, A. R., Cederwall, R., Chlond, A and Duynkerke, P. G., Golaz, J., Khairoutdinov, M., Lewellen, D. C., Lock, A. P., MacVean, M. K., Moeng, C. H., Neggers, R. A. J., Siebesma, A. P., and Stevens, B.: Large-eddy simulation of the diurnal cycle of shallow cumulus convection overland, Q. J. Roy. Meteorol. Soc., 128, 1075-1093, https://doi.org/10.1256/003590002320373210, 2002.

Brown, N., Weiland, M., Hill, A., Shipway, B., Maynard, C., Allen, T., and Rezny, M.: A Highly Scalable Met Office NERC Cloud Model, in: Proceedings of the 3rd International Conference on Exascale Applications and Software, 132-137, University of Edinburgh, Edinburgh, Scotland, UK, available at: http://dl.acm. org/citation.cfm?id=2820083.2820108 (last access: 30 September 2018), 2015.

Clark, P. D., Choularton, T. W., Brown, P. R. A., Field, P. R., Illingworth, A. J., and Hogan, R. J.: Numerical modelling of mixed-phase frontal clouds observed during the CWVC project, Q. J. Roy. Meteorol. Soc., 131, 1677-1693, https://doi.org/10.1256/qj.03.210, 2005.

Connolly, P. J., Choularton, T. W., Gallagher, M. W., Bower, K. N., Flynn, M. J., and Whiteway, J. A.: Cloud-resolving simulations of intense tropical Hector thunderstorms: Implications for aerosol-cloud interactions, Q. J. Roy. Meteorol. Soc., 132, 30793106, https://doi.org/10.1256/qj.05.86, 2006.

Connolly, P. J., Vaughan, G., Cook, P., Allen, G., Coe, H., Choularton, T. W., Dearden, C., and Hill, A.: Modelling the effects of gravity waves on stratocumulus clouds observed during VOCALS-UK, Atmos. Chem. Phys., 13, 7133-7152, https://doi.org/10.5194/acp-13-7133-2013, 2013.

Dee, D. P., Uppala, S. M., Simmons, A. J., Berrisford, P., Poli, P., Kobayashi, S., Andrae, U., Balmaseda, M. A., Balsamo, G., Bauer, P., Bechtold, P., Beljaars, A. C. M., van de Berg, L., Bidlot, J., Bormann, N., Delsol, C., Dragani, R., Fuentes, M., Geer, A. J., Haimberger, L., Healy, S. B., Hersbach, H., Hólm, E. V., Isaksen, L., Kållberg, P., Köhler, M., Matricardi, M., McNally, A. P., Monge-Sanz, B. M., Morcrette, J.-J., Park, B.-K., Peubey, C., de Rosnay, P., Tavolato, C., Thépaut, J.-N., and Vitart, F.: The ERA-Interim reanalysis: configuration and performance of the data assimilation system, Q. J. Roy. Meteorol. Soc., 137, 553597, https://doi.org/10.1002/qj.828, 2011.

Derrien, S., Bezombes, Y., Bret, G., Gabella, O., Jarnot, C., Medina, P., Piques, E., Delon, C., Dione, C., Campistron, B., Durand, P., Jambert, C., Lohou, F., Lothon, M., Pacifico, F., and Meyerfeld, Y.: DACCIWA field campaign, Savè super-site, UPS instrumentation; SEDOO OMP, https://doi.org/10.6096/DACCIWA.1618, 2016.

Dione, C., Lohou, F., Lothon, M., Adler, B., Babic, K., Kalthoff, N., Pedruzo-Bagazgoitia, X., Bezombes, Y., and Gabella, O.: Intraseasonal evolution of the most important low-troposphere dynamical structures over southern West Africa during DACCIWA field campaign, in preparation, Atmos. Chem. Phys., 2018.

Edwards, J. M. and Slingo, A.: Studies with a flexible new radiation code. I: Choosing a configuration for a largescale model, Q. J. Roy. Meteorol. Soc., 122, 689-719, https://doi.org/10.1002/qj.49712253107, 1996.

Flamant, C., Knippertz, P., Fink, A., Akpo, A., Brooks, B., Chiu, C., Coe, H., Danuor, S., Evans, M., Jegede, O., Kalthoff, N., Konaré, A., Liousse, C., Lohou, F., Mari, C., Schlager, H., Schwarzenboeck, A., Adler, B., Amekudzi, L., Aeyee, J., Ayoola, M., Bessardon, G., Bower, K., Burnet, F., Catoire, V., Colomb, A., Fossu-Amankwah, K., Lee, J., Lothon, M., Manaran, M., Marsham, J., Meynadier, R., Ngamini, J.-B., Rosenberg, P., Sauer, D., Schneider, J., Smith, V., Stratmann, G., Voigt, C., and Yoboue, V.: The Dynamics-Aerosol-Chemistry-Cloud Interactions in West Africa field campaigns: Overview and research highlights, B. Am. Meteor. Soc., https://doi.org/10.1175/BAMS-D-16-0256.1, 2017.

Garcia-Carreras, L., Marsham, J. H., Parker, D. J., Bain, C. L., Milton, S., Saci, A., Salah-Ferroudj, M., Ouchene, B., and Washington, R.: The impact of convective cold pool outflows on model biases in the Sahara, Geophys. Res. Lett., 40, 1647-1652, https://doi.org/10.1002/grl.50239, 2013.

Gounou, A., Guichard, F., and Couvreux, F.: Observations of Diurnal Cycles Over a West African Meridional Transect: Pre-Monsoon and Full-Monsoon Seasons, Bound.-Lay. Meteorol., 144, 329-357, https://doi.org/10.1007/s10546-012-9723-8, 2012.

Gray, M. E. B., Petch, J., Derbyshire, S. H., Brown, A. R., Lock, A. P., Swann, H. A., and Brown, P. R. A.: Version 2.3 of the Met Office large eddy model: Part II Scientific Documentation, Apr turbulence and diffusion report 276, Met Office, Fitroy Road, Exeter EX1 3PB, UK, 2001.

Grosvenor, D. P., Field, P. R., Hill, A. A., and Shipway, B. J.: The relative importance of macrophysical and cloud albedo changes for aerosol-induced radiative effects in closed-cell stratocumulus: insight from the modelling of a case study, Atmos. Chem. Phys., 17, 5155-5183, https://doi.org/10.5194/acp17-5155-2017, 2017.

Handwerker, J., Scheer, S., and Gamer, T.: DACCIWA field campaign, Savè super-site, Cloud and precipitation, SEDOO OMP., https://doi.org/10.6096/DACCIWA.1686, 2016.

Hannak, L., Knippertz, P., Fink, A. H., A. Kniffka, A., and Pante, G.: Why Do Global Climate Models Struggle to Represent Low-Level Clouds in the West African Summer Monsoon?, J. Clim., 30, 1665-1687, https://doi.org/10.1175/JCLI-D16-0451.1, 2017. 
Haslett, S. L., Taylor, J. W., Evans, M., Morris, E., Vogel, B., Dajuma, A., Brito, J., Batenburg, A. M., Borrmann, S., Schneider, J., Schulz, C., Denjean, C., Bourrianne, T., Knippertz, P., Dupuy, R., Schwarzenböck, A., Sauer, D., Flamant, C., Dorsey, J., Crawford, I., and Coe, H.: Biomass burning from central Africa dominates regional pollution across the West African region during the monsoon season, in preparation, Atmos. Chem. Phys., 2018.

Jones, C. R., Bretherton, C. S., and Leon, D.: Coupled vs. decoupled boundary layers in VOCALS-REx, Atmos. Chem. Phys., 11, 7143-7153, https://doi.org/10.5194/acp-11-7143-2011, 2011.

Kalthoff, N., Lohou, F., Brooks, B., Jegede, G., Adler, B., Babic, K., Dione, C., Ajao, A., Amekudzi, L. K., Aryee, J. N. A., Ayoola, M., Bessardon, G., Danuor, S. K., Handwerker, J., Kohler, M., Lothon, M., Pedruzo-Bagazgoitia, X., Smith, V., Sunmonu, L., Wieser, A., Fink, A. H., and Knippertz, P.: An overview of the diurnal cycle of the atmospheric boundary layer during the West African monsoon season: results from the 2016 observational campaign, Atmos. Chem. Phys., 18, 2913-2928, https://doi.org/10.5194/acp-18-2913-2018, 2018.

Khairoutdinov, M. and Kogan, Y.: A new cloud physics parameterization in a large-eddy simulation model of marine stratocumulus, Mon. Weather Rev., 128, 229-243, https://doi.org/10.1175/15200493(2000)128<0229:ANCPPI>2.0.CO;2, 2000.

Knippertz, P., Fink, A. H., Schuster, R., Trentmann, J., Schrage, J. M., and Yorke, C.: Ultra-low clouds over the southern West African monsoon region, Geophys. Res. Lett., 38, L21808, https://doi.org/10.1029/2011GL049278, 2011.

Knippertz, P., Coe, H., Chiu, J. C., Evans, M. J., Fink, A. H., Kalthoff, N., Liousse, C., Mari, C., Allan, R. P., Brooks, B., Danour, S., Flamant, C., Jegede, O. O., Lohou, F., and Marsham, J. H.: The DACCIWA Project Dynamics-AerosolChemistry-Cloud Interactions in West Africa, B. Am. Meteor. Soc., 96, 1451-1460, https://doi.org/10.1175/BAMS-D-1400108.1, 2015a.

Knippertz, P., Evans, M. J., Field, P. R., Fink, A. H., Liousse, C., and Marsham, J. H.: The possible role of local air pollution in climate change in West Africa, Nat. Clim. Change, 5, 815-822, https://doi.org/10.1038/NCLIMATE2727, 2015b.

Knippertz, P., Fink, A. H., Deroubaix, A., Morris, E., Tocquer, F., Evans, M. J., Flamant, C., Gaetani, M., Lavaysse, C., Mari, C., Marsham, J. H., Meynadier, R., Affo-Dogo, A., Bahaga, T., Brosse, F., Deetz, K., Guebsi, R., Latifou, I., Maranan, M., Rosenberg, P. D., and Schlueter, A.: A meteorological and chemical overview of the DACCIWA field campaign in West Africa in June-July 2016, Atmos. Chem. Phys., 17, 10893-10918, https://doi.org/10.5194/acp-17-10893-2017, 2017.

Kohler, M., Kalthoff, N., Seringer, J., and Kraut, S.: DACCIWA field campaign, Savè super-site, Surface measurements, SEDOO OMP, https://doi.org/10.6096/DACCIWA.1690, 2016.

LeBarbé, L., Lebel, T., and Tapsoba, D.: Rainfall variability in West Africa during the years 1950-90, J. Clim., 15, 187-202, https://doi.org/10.1175/15200442(2002)015<0187:RVIWAD>2.0.CO;2, 2002.

Lothon, M., Said, F., Lohou, F., and Campistron, B.: Observation of the diurnal cycle in the low troposphere of West Africa, Mon. Weather Rev., 136, 3477-3500, https://doi.org/10.1175/2008MWR2427.1, 2008.

Marsham, J., Dixon, N. S., Garcia-Carreras, L., Lister, G. M. S., Parker, D. J., and Birch, P. K. C. E.: The role of moist convection in the West African monsoon system: Insights from continentalscale convection-permitting simulations, Geophys. Res. Lett., 40, 1843-1849, https://doi.org/10.1002/grl.50347, 2013.

Marsham, J. H., Dobbie, S., and Hogan, R. J.: Evaluation of a large-eddy model simulation of a mixed-phase altocumulus cloud using microwave radiometer, lidar and Doppler radar data, Q. J. Roy. Meteorol. Soc., 132, 1693-1715, https://doi.org/10.1256/qj.05.145, 2006.

Merk, D., Deneke, H., Pospichal, B., and Seifert, P.: Investigation of the adiabatic assumption for estimating cloud micro- and macrophysical properties from satellite and ground observations, Atmos. Chem. Phys., 16, 933-952, https://doi.org/10.5194/acp-16933-2016, 2016.

Miltenberger, A. K., Field, P. R., Hill, A. A., Rosenberg, P., Shipway, B. J., Wilkinson, J. M., Scovell, R., and Blyth, A. M.: Aerosol-cloud interactions in mixed-phase convective clouds Part 1: Aerosol perturbations, Atmos. Chem. Phys., 18, 31193145, https://doi.org/10.5194/acp-18-3119-2018, 2018.

Parker, D. J., Burton, R. R., Diongue-Niang, A., Ellis, R. J., Felton, M., Taylor, C. M., Thorncroft, C. D., Bessemoulin, P., and Tompkins, A. M.: The diurnal cycle of the West African monsoon circulation, Q. J. Roy. Meteorol. Soc., 131, 2839-2860, https://doi.org/10.1256/qj.04.52, 2005.

Schrage, J. M. and Fink, A. H.: Nocturnal Continental Low-Level Stratus over Tropical West Africa: Observations and Possible Mechanisms Controlling Its Onset, Mon. Weather Rev., 140, 1794-1809, https://doi.org/10.1175/MWR-D-11-00172.1, 2012.

Schuster, R., P. and Knippertz, A. H. F.: Formation and Maintenance of Nocturnal Low-Level Stratus over the Southern West African Monsoon Region during AMMA 2006, J. Atmos. Sci., 70, 23372355, https://doi.org/10.1175/JAS-D-12-0241.1, 2013.

Stevens, R. G., Loewe, K., Dearden, C., Dimitrelos, A., Possner, A., Eirund, G. K., Raatikainen, T., Hill, A. A., Shipway, B. J., Wilkinson, J., Romakkaniemi, S., Tonttila, J., Laaksonen, A., Korhonen, H., Connolly, P., Lohmann, U., Hoose, C., Ekman, A. M. L., Carslaw, K. S., and Field, P. R.: A model intercomparison of $\mathrm{CCN}$-limited tenuous clouds in the high Arctic, Atmos. Chem. Phys., 18, 11041-11071, https://doi.org/10.5194/acp-18-110412018, 2018.

Sultan, B. and Janicot, S.: Abrupt shift of the ITCZ over West Africa and intra-seasonal variability, Geophys. Res. Lett., 27, 33533356, https://doi.org/10.1029/1999GL011285, 2000.

van der Linden, R., Fink, A. H., and Redl, R.: Satellite-based climatology of low-level continental clouds in southern West Africa during the summer monsoon season, J. Geophys. Res.-Atmos., 120, 1186-1201, https://doi.org/10.1002/2014JD022614, 2015.

Walters, D., Boutle, I., Brooks, M., Melvin, T., Stratton, R., Vosper, S., Wells, H., Williams, K., Wood, N., Allen, T., Bushell, A., Copsey, D., Earnshaw, P., Edwards, J., Gross, M., Hardiman, S., Harris, C., Heming, J., Klingaman, N., Levine, R., Manners, J., Martin, G., Milton, S., Mittermaier, M., Morcrette, C., Riddick, T., Roberts, M., Sanchez, C., Selwood, P., Stirling, A., Smith, C., Suri, D., Tennant, W., Vidale, P. L., Wilkinson, J., Willett, M., Woolnough, S., and Xavier, P.: The Met Office Unified Model Global Atmosphere 6.0/6.1 and JULES Global Land 6.0/6.1 configurations, Geosci. Model Dev., 10, 14871520, https://doi.org/10.5194/gmd-10-1487-2017, 2017. 
Wieser, A., Adler, B., and Deny, B.: DACCIWA field campaign, Savè super-site, Thermodynamic data sets; SEDOO OMP, https://doi.org/10.6096/DACCIWA.1659, 2016.

Young, G., Connolly, P. J., Jones, H. M., and Choularton, T. W.: Microphysical sensitivity of coupled springtime Arctic stratocumulus to modelled primary ice over the ice pack, marginal ice, and ocean, Atmos. Chem. Phys., 17, 4209-4227, https://doi.org/10.5194/acp-17-4209-2017, 2017. 